\title{
AC 2010-2377: CENTER FOR LIFE SCIENCES TECHNOLOGY - A MODEL FOR INTEGRATION OF EDUCATION, RESEARCH, OUTREACH AND WORKFORCE DEVELOPMENT
}

Rupa Iyer, University of Houston 


\title{
Center for Life Sciences Technology - A Model for Integration of Education, Research, Outreach and Workforce Development
}

\begin{abstract}
The biotechnology industry that originated in the 1970's has since mushroomed from $\$ 8$ billion in revenues in 1992 to $\$ 50.7$ billion and is one of the most research intensive industries in the world. While biotechnology originated based largely on recombinant DNA techniques, tremendous research in biotechnology has led to the convergence of advanced technologies in engineering, biological sciences and information technology. Based in the University of Houston's College of Technology, the Center for life Sciences Technology (CLiST) is positioned to be a key component in statewide effort to support the biotechnology and Life Sciences industry in Texas. The Center's blend of academic, research, outreach and workforce is unique and serves as a model for industry-academic collaboration focused on preparing 21 st century workforce. The goals of the center are:
\end{abstract}

1. Provide interdisciplinary research based educational programs

2. Conduct outreach programs to nurture Science, Technology Engineering and Math (STEM) education

3. Foster a collaborative environment to support the biotech industry through training, research and best practice sharing.

4. Engage in high impact research with an emphasis on environmental biotechnology.

The first initiative of the center was to establish a new undergraduate major in biotechnology. This new degree program was developed in collaboration with industry and academic partners and offers two tracks, one in bioinformatics and the other in bioprocessing. The laboratory curriculum is a research -based curriculum and uses a pesticide degrading bacteria as a model to train students on techniques and applications of biotechnology. In summer, we offer outreach programs to train high school teachers and students. For local incumbent biotech workers, we offer workforce development certificate courses to help them stay current and upgrade their skills. The Center provides access to space, expertise and equipment to local biotech companies and serves as a platform for innovation and institutional collaboration.

\section{Introduction}

The U. S Department of Labor has identified Biotechnology as one of the high profile growth industries in the nation. The state of Texas has also identified Biotechnology as one of the six primary clusters for Texas. However, despite significant strengths Texas has comparatively few companies working in these areas. This is reflected in the relatively small workforce in Texas, about 10,000 , which is less than $4 \%$ of the national workforce in the Biotech and Life Sciences 
cluster. According to the Governor's Competitive Council, Texas must continue to build a workforce to support this cluster and implement focused strategies to increase the number of companies. One factor that is playing a major role in the city's lack of competitiveness in attracting the biotechnology industry, despite its strong university and medical biotechnology research activities, is the lack of a trained and readily available workforce.

To address this challenge, the Center for Life Sciences Technology was created in response to recommendations by a task force consisting of representatives from economic development groups, local biotech industry, the Texas medical center and its constituent institutions, area universities and colleges, non-profit organizations, economic development groups and governmental agencies. The University's College of Technology took the lead to function as a catalyst among cluster stakeholders for the purpose of planning and affecting a visible continuum of education, training and research opportunities. Although the Center was to be housed in the College of Technology its work was to be interdisciplinary involving several University's Colleges as well as regional community colleges, other universities, local industry, local agencies, and not-for-profit organizations.

There are numerous centers for learning and teaching at universities and colleges around the nation. However very few concentrate on developing innovative educational programs, supporting workforce development, conducting outreach and training activities and provide resources to share curriculum, and disseminate industry information.

\section{Organization and Governance}

Operational and technical responsibility for Center for Life Sciences Technology was under the Director of the Center who was appointed by the Dean of the College of Technology. The Policy Advisory Board was created to provide oversight for the Center. The policy Advisory Board consisted of both university representatives as well as external representatives from government, regional industry, the Texas Medical Center and constituent institutions and regional educational institutions. The Board meets quarterly and advises the Director and the College of Technology Dean on the overall direction of the Center's research programs and major initiatives that the institute may undertake.

The Center was officially approved by the office of Research in 2006 and was called the Center for Life Sciences Technology (CLiST). The mission of the center was to be a key component in the statewide effort to support the biotechnology and life sciences cluster, the center supports this mission by

- Developing innovative interdisciplinary research-based education and certification programs in biotechnology to build a competitive $21^{\text {st }}$ century workforce

- Supporting the biotechnology and life sciences industry cluster through training, education and best practice sharing 
- Conducting outreach programs to nurture Science, Technology, Engineering, and Mathematics (STEM) education

- Engaging in high impact research with an emphasis on Environmental Biotechnology

\section{Academic Program}

One of the first initiatives developed by the Center for Life Sciences Technology was the new undergraduate Bachelor's in Biotechnology. Strongly interdisciplinary, this innovative program was developed in collaboration with industry and academic partners. The program's objective is to prepare students for employment opportunities in the critically important and dynamic biotechnology industry. In addition, the program also provided students with knowledge and a core set of skills that span across basic sciences, technology, engineering, and mathematics (STEM) education. With an emphasis on environmental biotechnology, this is the first program in the state of Texas that integrates bioprocessing, nanobiotechnolgy, bioinformatics and environmental biotechnology.

The program is specifically designed to:

- Develop adaptable students with a strong foundation in skills that are relevant to the changing world of biotechnology

- Provide students with practical training in the skills and techniques of biotechnology.

- Integrate the laboratory and lecture components of the program through the use of an experimental approach to learning

- Combine practical, hands-on biotechnology training with cutting-edge biotechnology research and teaching

This major will prepare students for:

- Graduate school or entry into a research laboratory

- Entry into the biotechnology industry

Two curriculum tracks, Bioprocessing and Bioinformatics were offered to give students the flexibility to tailor their degree based on their interests, educational background and career goals. These tracks, in combination with core courses, were intended to provide our students with a broad exposure to the field of biotechnology. The presence of the Texas Medical Center in the greater Houston area and a growing biotechnology and pharmaceutical industry places this program at the forefront of Biotechnology Education.

The current Director developed this multidisciplinary undergraduate curriculum in collaboration with the academic and industry partners. In addition, she collaborated with Dr. Melinda Wales of Texas A \& M University and Reactive Surfaces, an Austin-based biotechnology company, and incorporated her research into the development of a project-based undergraduate laboratory

curriculum. The new laboratory curriculum infuses twenty years of research into the 
undergraduate biotechnology lab and provides students with hands- on experience with some of the new and emerging techniques in biotechnology to better prepare our undergraduates for employment in the biotechnology industry or entry into graduate school.

\section{Training Programs}

Due to a lack of new flexible training modules to keep up with the rapid changes in the biotechnology and life science industry, the Center offering short courses in specific topics in collaboration with industry partners. These short courses provide a strong linkage between industry and education to communicate ongoing changes. The goal was to develop career opportunities for students at various skill levels, including incumbent and dislocated workers, to obtain training to upgrade skills and traditional students entering the workforce for the first time. The modular delivery of the courses allows students to obtain the necessary training during a single class session. The courses address topical and timely subjects in the form of workshops or mini- certificates based on information gathered from our industry and academia partners. In collaboration with the local biotechnology industry we developed courses such as Current Good Manufacturing Practices, Biotechnology Techniques, Quality Assurance, Quality Control, Application of Bioinformatics and Bioprocessing.

\section{Summer Outreach Activities}

Raising the performance of students including underrepresented groups in STEM-related subjects - and sparking their enthusiasm for those disciplines is a top priority of the Center. The new interdisciplinary biotechnology degree program offered by the College of Technology embodies all STEM concepts and will provides a platform for STEM related studies to students entering the program.

To motivate and recruit students in STEM related fields, we offered Biotechnology summer camps for high school students. Our goal in this program was to introduce motivated high school students to the techniques used in modern biotechnology research. The camps familiarized students with concepts and techniques of biotechnology. Students also explored topics in general areas of science and technology including: microbiology, biochemistry and molecular biology. Lab activities included growth, isolation and characterization of microbes, DNA isolation analysis and amplification (PCR) using standard laboratory model organisms (bacteria and yeast). Program format was as follows:

Day 1: students were given overview of biotechnology and its applications in agriculture, forensics, medicine and environment, which followed by introduction to basic laboratory techniques, experimental design and data analysis.

Day 2: students toured the sensor network lab and were given demonstration on remote sensing dives that monitor patient health. They then toured the library where they learned how to use the library resources to conduct research on the topic of their interest. The camp concludes by 
students using library resources, computer and lab skills to study protein structure and function.

\section{Web Portal}

The CLiST Web portal was developed to share curriculum, disseminate industry information, and create a consortium of higher education institutions and private sector enterprises that addresses biotechnology education and training requirements. The web-portal

www.texasbiotch.org contains industry calendars and news, career opportunities, support for the education institutions and support for economic development organizations.

\section{Funding}

All the initiatives developed by the center were supported by funding from the state and federal agencies. This included grants from Texas Workforce Commission and the National Science Foundation for a total of over 1.6milion dollars. The funds provided seed funding for new program development, equipment and supplies for the new proposed biotechnology laboratories. Funding also enabled us to sustain Web portal development of the CLiST and outreach activities to area high schools to begin the pipeline of biotech education.

\section{REFERENCES}

[1] Ashby, Cornelia M. 2006. Higher Education: Science, Technology, Engineering, and Mathematics Trends and the Role of Federal Programs, Testimony before the Committee on Education and the Workforce, House of Representatives. GAO-06-702T, U.S. Government Accountability Office, 441 G Street NW, Washington, DC 20548, Tel: 202-512-6000; Web site: http://www.gao/gov

[2] Handelsman J., D. Ebert-May, Beichner R., Bruns P., Chnag A., DeHann R., Gentile J., Lauffer S., Stewart J., Tilghman S.M., and Wood, W.B. Scientific teaching. Science 304:521522. 
[3] Rothman, F.G. and Narum, J.L. Then, now, and the in the next decade: a commentary on strengthening undergraduate science, mathematics, engineering and technology education. Project Kaleidoscope, Washington, DC.

[4] Tadmor, Brigitta and Tidor, Bruce. Interdisciplinary research and education at the biology-engineering-computer science interface: a perspective (reprinted article). Drug Discovery Today, Volume 10, Issues 23-24, December 2005, pp 1706-1712.

[5] Kenny, R.W., and Boyer commission on "Educating Undergraduates in the research university”. Reinventing undergraduate education: a blueprint for America's research universities, 1998. State University of New York-Stonybrook, Stonybrook, NY.

[6] Wyckoff, S. Changing the culture of undergraduate science teaching. J. Coll.sci.Teach. 29:409-414, 2008

[7]Roppel, T. A., Hung, J. Y., Wentworth, S. W., and Hodel, A. S. An interdisciplinary laboratory sequence in electrical and computer engineering: curriculum design and assessment results. IEEE Transactions on Education, vol. 43, issue 2, 2000. pp. 143-152

[8] Biernacki, Joseph J, and Wilson, Christopher D. Interdisciplinary laboratory in advanced materials: A team-oriented inquiry-based approach. Journal of Engineering Education, 2001

[9] Iyer, Rupa S. and Fitzgibbon, William. Building the future biotechnology workforce: A University of Houston Model. Journal of Commercial Biotechnology, Vol 15, number 2, 2009, pp.171-182. 